\title{
UM CURRÍCULO NA INTEGRAÇÃO ENSINO-SERVIÇO DO PROGRAMA MAIS MÉDICOS E POSSÍVEIS EFEITOS CULTURAIS
}

\author{
A SYLLABUS IN THE TEACHING-SERVICE INTEGRATION OF THE MORE \\ DOCTORS PROGRAM AND POSSIBLE CULTURAL EFFECTS
}

\begin{abstract}
Maria Patrícia Silva ${ }^{1}$ iD (https://orcid.org/0000-0003-4477-2419) Marlucy Alves Paraíso² (iD)(https://orcid.org/0000-0002$3542-4650)$

${ }^{1}$ Universidade do Estado de Minas Gerais, Unidade de Ibirité, Departamento de Educação e Ciências Humanas. Belo Horizonte, MG, Brasil. <maria.patriciafjp@gmail.com>
\end{abstract}

${ }^{2}$ Universidade Federal de Minas Gerais, Faculdade de Educação, Departamento de Administração Escolar. Belo Horizonte, Minas Gerais, Brasil.

Resumo O estudo teve como objetivo identificar mudanças em curso na formação de profissionais da medicina desencadeadas pelas demandas do Programa Mais Médicos. As discussões foram guiadas de acordo com formulações dos estudos culturais no campo do currículo. Analisaram-se artigos e relatórios de pesquisa sobre efeitos que conectam trabalho, aprendizado e mudanças nas práticas de médicos inseridos no Programa. O contexto de fortalecimento e construção do Sistema Único de Saúde, algumas reformas e agendas políticas que alcançam o currículo formal e, recentemente, a implementação do Programa Mais Médicos propriamente dito, são ações identificadas como possibilidades criadas e como espaços onde acontecem novas práticas no interior de uma cultura profissional ainda biomédica/flexneriana. Os resultados confirmaram micromudanças no Programas Mais Médicos que são tratadas como efeitos culturais, postas em prática na integração ensino-serviço, em que se verifica a aproximação de um trabalho mais humanizado.

Palavras-chave Programa Mais Médicos; educação e saúde; currículo; estudos culturais.
Abstract The study had the goal of identifying current changes in the training of medicine professionals that have been brought about by the demands of the More Doctors Program ('Programa Mais Médicos,' in Portuguese) in Brazil. The discussions were guided by formulations of the cultural studies in the field of the syllabus. We analyzed articles and research reports on the effects that connect work, learning and changes in the practices of the doctors who integrate the Program. The context of strengthening and development of the Unified Health System ('Sistema Único de Saúde,' in Portuguese), certain reforms and political agendas that affect the formal syllabus, and, recently, the implementation of the More Doctors Program itself, are actions that are identified as possibilities created and as spaces where new practices take place within a professional culture that is still biomedical/flexnerian. The results confirmed micro changes in the More Doctors Program that are treated as cultural effects and put into practice in the teaching-service integration, in which the approach of a more humanized work is observed. Keywords More Doctors Program; education and health; syllabus; cultural studies. 


\section{Introdução}

A temática deste trabalho ainda é pouco analisada no campo de pesquisas que tratam do currículo que forma médicos no Brasil, ${ }^{1}$ o que nos leva a crer que este é um debate profícuo e relevante. A profissão médica é constituída em uma cultura ligada a certo status social. Uma das explicações possíveis é que a carreira médica envolve um "estereótipo de profissão com alto grau de autonomia técnica (saber) e econômica (mercado de trabalho)" (Machado, 1997, p. 21) e foi construída, desde sua criação, para os filhos da elite brasileira (Coradini, 2005). É uma profissão que representa grandes demandas para atender às necessidades da população periférica no Brasil. Entretanto, essas áreas são as que menos atraem médicos. Na perspectiva de solucionar tal questão foi criado o Programa Mais Médicos (PMM), por meio da lei $\mathrm{n}$. 12.871, com o objetivo amplo de realizar o provimento emergencial de médicos (Brasil, 2013).

A formação de médicos que façam a integração ensino-serviço é uma característica inerente às mudanças recentes do modelo de assistência à saúde no Brasil, com a criação do Sistema Único de Saúde (SUS), reafirmada no PMM. Nesse caminho, argumentamos que há no PMM um currículo voltado para estabelecer mudanças na prática médica. Afinal, o currículo presente no contexto do Programa pressupõe um modelo diferenciado do tradicionalmente instituído no Brasil, este último fundamentado em um trabalho especializado, biologicista e voltado para o mercado de trabalho privado. ${ }^{2}$ Para apresentar nosso argumento, dividimos assim o artigo: uma contextualização sobre a criação do PMM; a aproximação entre a criação do SUS e dois modelos de assistência à saúde, que afetam o currículo para médicos no Brasil; os significados de cultura e currículo; e alguns efeitos culturais do Programa, com o estabelecimento de novas relações que podem ser identificadas como mudanças na abordagem clínica do PMM, incluindo ações e práticas mais humanísticas e de maneira integral. Para tanto, realizamos uma pesquisa bibliográfica para identificar novos processos sociais e culturais da relação prática médica e abordagem clínica no contexto do PMM.

\section{O caminho da pesquisa bibliográfica para identificar efeitos culturais do PMM}

A fim de localizar os efeitos culturais do Programa, realizou-se um levantamento de estudos que analisam o PMM, quando foram consultados trabalhos divulgados na Plataforma de Conhecimentos do Programa Mais Médicos, ${ }^{3}$ com corte temporal de janeiro de 2015 até maio de 2018. Localizaram-se quarenta pesquisas, ainda em desenvolvimento. Destas, não havia nenhuma que tivesse como objeto principal a relação currículo e PMM. 
Na mesma plataforma, consultamos os artigos publicados. Do total de 412, apenas 15 mencionavam o termo 'currículo'. Entretanto, por tomarem o significado de 'currículo' como o mesmo que 'grade curricular', sem menção a práticas médicas, não os utilizamos. A segunda tentativa foi encontrar relatórios de pesquisa. Neste caso, a busca foi direcionada por dois termos: 'educação' e 'trabalho médico', mas localizamos apenas uma pesquisa.

Além da Plataforma de Conhecimentos do Programa Mais Médicos, foi realizado um levantamento entre publicações do campo da saúde coletiva de 2015 a 2018, especialmente nas seguintes revistas: Tempus: Actas de Saúde Coletiva, Saúde e Sociedade e Ciência \& Saúde Coletiva. Dos artigos, selecionamos três que abordavam as temáticas 'educação' e 'trabalho dos médicos no contexto do $\mathrm{PMM}^{\prime}$, os quais aproximavam do debate proposto em nossa linha de análise.

A terceira tentativa, em de agosto de 2018, foi uma pesquisa em sites de programas de pós-graduação, dos quais citamos a Universidade de São Paulo e o Instituto de Medicina da Universidade do Rio de Janeiro, com o intuito de localizar pesquisas que tivessem como foco a tessitura 'PMM, efeitos culturais, currículo e/ou educação'. Ainda tomamos como parte do estudo uma releitura de entrevistas realizadas por Silva e Fahel (2017) com médicos do Programa. ${ }^{4}$ No que diz respeito aos critérios para a seleção das publicações, foram considerados como critérios de inclusão trabalhos que conectassem 'Programa Mais Médicos', 'currículo', 'processo de trabalho' e 'educação' em seu foco de estudo. ${ }^{5}$ No Quadro 1, apresentamos a relação de artigos e estudos (por autores), a base de pesquisa e como eles mencionam mudanças ocasionadas na relação trabalho e educação no contexto do PMM, o que chamamos de efeitos culturais.

\begin{tabular}{|c|c|c|c|}
\hline \multicolumn{4}{|c|}{ Relação de artigos e estudos por efeitos culturais mencionados } \\
\hline $\begin{array}{l}\text { Tipo de } \\
\text { trabalho }\end{array}$ & Título & Autoria & Efeitos culturais \\
\hline Artigo & $\begin{array}{l}\text { Educação em saúde no Programa } \\
\text { Mais Médicos para o Brasil: o papel do } \\
\text { supervisor no processo educacional }\end{array}$ & $\begin{array}{l}\text { Rodrigues, Quaresma e } \\
\text { Monteiro (2015) }\end{array}$ & $\begin{array}{l}\text { Implementação de } \\
\text { educação permanente } \\
\text { e mudança de prática } \\
\text { em ações de educação e } \\
\text { saúde com a população }\end{array}$ \\
\hline Artigo & $\begin{array}{l}\text { O supervisor e as estratégias educacionais } \\
\text { dos encontros locorregionais no Programa } \\
\text { Mais Médicos do Brasil: reflexões acerca } \\
\text { de concepções e práticas }\end{array}$ & Engstrom et al. (2016) & $\begin{array}{l}\text { Educação permanente e } \\
\text { mudança de práticas }\end{array}$ \\
\hline Artigo & $\begin{array}{l}\text { Médicos estrangeiros no Brasil: a arte do } \\
\text { saber olhar, escutar e tocar }\end{array}$ & Santos et al. (2016) & $\begin{array}{l}\text { O encontro de médicos } \\
\text { cubanos e brasileiros e a } \\
\text { humanização }\end{array}$ \\
\hline $\begin{array}{l}\text { Relatório de } \\
\text { pesquisa }\end{array}$ & $\begin{array}{l}\text { Programa Mais Médicos no município do } \\
\text { Rio de Janeiro: mais acesso, equidade e } \\
\text { resolutividade na APS }\end{array}$ & $\begin{array}{l}\text { Organização Pan- } \\
\text { Americana da Saúde } \\
\text { (2016) }\end{array}$ & $\begin{array}{l}\text { Aprendizado para } \\
\text { médicos brasileiros }\end{array}$ \\
\hline $\begin{array}{l}\text { Relatório de } \\
\text { pesquisa }\end{array}$ & $\begin{array}{l}\text { Programa Mais Médicos em Minas Gerais: } \\
\text { uma análise sobre os principais desafios } \\
\text { e avanços presentes no processo de } \\
\text { trabalho e assistência na atenção básica } \\
\text { em municípios da Região Metropolitana } \\
\text { de Belo Horizonte/MG }\end{array}$ & Silva e Fahel (2017) & $\begin{array}{l}\text { Aprendizagem na } \\
\text { integração ensino- } \\
\text { serviço, avanços em } \\
\text { conhecimentos em } \\
\text { relação à graduação }\end{array}$ \\
\hline
\end{tabular}




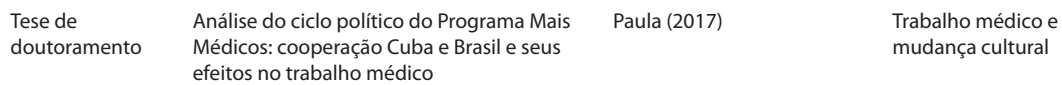

Os estudos mencionados não trataram exatamente de currículo, mas da possibilidade de aprendizagem e mudança no contexto do PMM, em uma perspectiva que aborda a relação currículo/educação para médicos e mudanças nas práticas realizadas nas unidades de saúde que receberam os médicos do Programa, por isso foram escolhidas para estudo.

Assim, encontramos sinalizações e aberturas, mesmo que pequenas. Nessas iniciativas, acreditamos estar diante de um cenário de possíveis mudanças construídas, como por exemplo na análise realizada por Rodrigues, Quaresma e Monteiro (2015), que trata de atividades de educação permanente e mudanças nas práticas médicas. A tese de doutoramento de Paula (2017) aborda o PMM no sertão da Paraíba, identifica uma mudança cultural e uma nova forma de exercício e acesso aos trabalhos médicos.

Além da busca citada, foram analisados estudos de Girardi e colaboradores (2016), Giovanella e colaboradores (2016), Silva Junior e Andrade (2016) e Cyrino e colaboradores (2015), no sentido de complementar o debate para uma primeira aproximação e contextualização do PMM - o que compõe matéria fundamental para a compreensão de suas origens e princípios.

\section{O Programa Mais Médicos: contextos e conexões}

A criação do PMM reitera os princípios de uma formação integral, inerente à concepção do SUS, como parte de um processo complexo e desafiador. A não aceitação do Programa, por exemplo, por uma parte considerável dos profissionais médicos foi um desses desafios. ${ }^{6} \mathrm{O}$ PMM somou-se a um conjunto de ações num cenário em que o governo federal assumiu a tarefa de formular políticas públicas para enfrentar problemas no desenvolvimento da atenção básica à saúde no país (Brasil, 2015), dentre os quais estava a escassez assistencial referente à quantidade de médicos (desigualmente) distribuídos pelo território nacional.

Para a economia, escassez refere-se àquelas situações nas quais os recursos são insuficientes para atender às demandas. Ao tratar da escassez de um bem, estamos dizendo que a quantidade existente é insuficiente para satisfazer as necessidades dos indivíduos. Entretanto, a escassez poderá variar em grau e sua natureza ser artificial, podendo os governos intervirem de maneira tal que o recurso em questão atenda a demanda (Girardi et al. 2016).

No caso da demanda por assistência à saúde, especificamente de médicos, a escassez remete a situações de carência e privação que são incompatíveis com os estados 
democráticos, uma vez que descrevem desigualdades no acesso a recursos sociais que podem impactar o curso de vida das pessoas (Girardi et al., 2016, p. 2.676).

No âmbito da articulação do PMM e do fortalecimento do SUS, há uma preocupação em fortalecer a atenção primária à saúde (APS), justamente em áreas de difícil acesso para o provimento de médicos. A APS - o primeiro nível de atenção dentro da organização do SUS $-^{7}$ realiza a promoção de saúde e a prevenção de riscos à saúde, em um trabalho integral e conectado com os outros níveis da atenção. Espera-se que a ação na APS inicie um trabalho que acolha, escute e ofereça resposta para a maioria dos problemas de saúde da população. E que possa diminuir danos e se responsabilizar pela efetividade do cuidado, em conexão com os outros pontos de atenção da rede, garantindo sua integralidade (Brasil, 2011). A importância da APS para a estruturação dos sistemas de saúde foi analisada por Starfield (2001), a qual ponderou que nenhuma sociedade dispõe amplamente de recursos econômicos para custear a saúde, em sua concepção mais completa.

O PMM direciona suas ações em grandes eixos, dos quais mencionamos: a inserção de novos médicos na APS em municípios de menor capacidade de atração; o avanço no número de graduações e residências no país; e uma reconfiguração do processo formativo estabelecido nas escolas médicas. O Programa se apresenta, portanto, com diferentes eixos, estrategicamente para atender às necessidades de saúde da população, que sofre com problemas que determinam o processo saúde-doença. Nesses lugares reside, quase sempre, aquela parte da população que, historicamente, teve seu direito à saúde negado, considerando-se o fato de que o sistema de saúde brasileiro foi construído num mix público e privado, o qual centralizou o acesso à assistência médica no hospital, e como uma medicina privatista (Menicucci, 2007).

Nessa linha, outro fenômeno importante é a configuração do modelo de educação médica prioritário no Brasil, em razão de ter sido guiado por uma concepção superespecializada e biomédica, por isso também chamado de modelo flexneriano. Na perspectiva flexneriana, um dos pontos fundamentais é a centralidade no hospital. A doença é considerada apenas em seu caráter biológico e unicausal, como parte de um processo natural. Logo, as dimensões sociais, psicológicas e econômicas não contam e não são implicadas no processo saúde-doença. Além da postura positivista, Flexner via a educação médica como um privilégio apenas para a elite, sem que esta oferecesse espaço para negros ou para mulheres (Pagliosa e Da Ros, 2008).

Em oposição, temos uma proposta com raiz no movimento pela reforma sanitária do SUS, presente nas diretrizes curriculares nacionais (DCNs) para graduação em medicina em 2001, reafirmada nas novas DCNs para gradu- 
ação em medicina em 2014, renovadas com o PMM. Dessa maneira, parte do processo de mudanças inerentes ao Programa está na revisão das DCNs para a graduação médica. Conforme observam Cyrino e colaboradores (2015), a proposta afirma uma formação em perspectiva que direcione ao trabalho na rede de atenção à saúde no SUS - formação que integre ensino-serviçocomunidade, em que pesem a integralidade e o caráter humanístico, que se afastam da concentração no modelo biomédico flexneriano.

Assim, fica a seguinte reflexão: haverá nas vivências dos médicos do PMM um currículo que mobilize e inicie um desmontar da perspectiva flexneriana? O PMM apresenta efeitos culturais, nos quais emergem mutações da prática médica. Para pensarmos sobre esses efeitos culturais, articularemos, mesmo que brevemente, uma aproximação com a perspectiva dos estudos culturais (ECs).

\section{Um currículo no Programa Mais Médicos e possíveis aproximações com os estudos culturais}

Os estudos culturais (ECs) têm origem em 1964, com a criação do Centro de Estudos Culturais Contemporâneos na Universidade de Birmingham (Inglaterra). Desde a criação, esse campo de investigação sempre é representado pela interdisciplinaridade. Os ECs ampliam e revigoram conceitos, dentre os quais a conexão cultura, identidade e diferença. Nesse campo, emerge assim um novo sentido para o currículo: "como um desses 'espaços' em que se dão lutas e conflitos culturais identitários" (Paraíso, 2004, p. 54, destaque no original).

Os estudiosos mais contundentes desse campo ponderam que os ECs são formações mutáveis e descentradas. Os seus itinerários de pesquisa, conforme observa Stuart Hall (1996), constituem um projeto político de oposição. Assim, por essas e outras características, os estudos culturais não pretendem ser uma disciplina acadêmica tradicional, com fronteiras e contornos nitidamente delineados. Ao contrário, constituem-se com abordagens e reflexões situadas na confluência de vários campos; a sua inspiração é romper com lógicas cristalizadas (Costa, Silveira e Sommer, 2003).

Ao tomarmos a lente dos ECs para estudar questões envoltas na configuração de um currículo inerente ao PMM, enfatizamos que a contextualização aí assumida penetra uma complexa articulação na qual estão envolvidos vidas cotidianas, agenda política, tradição, relações de poder, contextos plurais. Portanto, suas relações também o são. Nos ECs,

as práticas culturais com que operamos, bem como as formas culturais que elegemos considerar, atuam na construção dos contextos e na configuração de formas específicas de organização da vida humana, tendo, portanto, importantes 
consequências sobre o modo como a realidade se organiza e é vivida (Costa, Wortmann e Bonin, 2016, p. 519).

Nesse ponto, apresentamos uma importante chave do nosso estudo: um debate sobre representação/significado de currículo e sua conexão com a cultura na perspectiva dos estudos culturais. Para melhor compreensão de nosso argumento, desenvolvemo-lo da seguinte maneira: além de trabalhar com a ideia de representação na ótica dos estudos culturais, explicitamos a noção de currículo nessa perspectiva.

Para Hall, representar tem um lugar decisivo no âmbito dos estudos culturais, já que faz uso de uma linguagem que está investida de significado. “Representação significa utilizar a linguagem para, inteligivelmente, expressar algo sobre o mundo, ou representá-lo a outras pessoas" (Hall, 2016, p. 31). Cabe lembrar que a representação, sendo mais que isso, faz parte de um processo, como nos adverte Stuart Hall (2016). Nesse processo circular conectam signos, imagens, símbolos, que significam. Além disso, diversas dimensões estão interligadas, dimensões do mundo da cultura, da vida social.

Representação, linguagem e significado, em Stuart Hall, estão imbricados nesse emaranhado, ou melhor, em um circuito, que o autor chama de 'circuito da cultura' (Hall, 2016). A linguagem, nesse caso, não está limitada ao seu sentido restrito; é preciso entendê-la como um 'compartilhamento de significados' de um grupo ou sociedade. Por meio da linguagem o significado é repassado, porque todos se utilizam dela para representar o que desejam expressar ou transmitir, seja um conceito, seja uma ideia, um sentido - o que nos leva a entender 'representação' ${ }^{8}$ como uma prática discursiva, pois ela conecta linguagem, sentido e cultura. Dessa maneira, situamos representação muito além do que é linguagem; ela inclui relações de poder e conhecimento, situadas em determinados contextos e momentos históricos (Hall, 2016) ${ }^{9}$ do processo, chamado de circuito da cultura, pelo autor.

A representação, portanto, se faz como processo e como produto, possui uma certa relatividade, já que não é nunca fixa, estável, determinada.

A indeterminação é o que caracteriza tanto a significação quanto a representação.

[...] Ela é representação de alguma 'coisa', não por sua identidade, coincidência ou correspondência com essa 'coisa', mas por representá-la [...] como diferente de outras 'coisas' (Silva, 2001, p. 41, grifos no original).

Para esse trabalho, 'culturas' dizem respeito aos modos de vida, a tudo que permeia a vida social, ao que não é estritamente biológico ou geneticamente programado. Ainda dizem respeito aos significados compartilhados, a 
um conjunto de práticas. O que não é o mesmo que dizer que culturas sejam sempre homogêneas e imutáveis - pois "em toda cultura há sempre diversidade de significados a respeito de um tema e mais de uma maneira de representálo, de interpretá-lo" (Hall, 2016, p. 20). Desse modo, culturas dizem respeito ainda a interesses, valores, regras, instituições, posicionamentos, símbolos.

As culturas podem ser vistas como criação e produção, não possuidoras de um caráter final. Em face disso, para Hall (1997a, 1997b), cultura é possuidora de uma produtividade instável, sempre em movimento e em desconstrução. Além disso, sem limitar-se, se faz como remontagem e construção nas relações de troca e negociações, relações de conflito e relações de poder.

A cultura é o que dá significado à vida social: "a cultura não é nada mais do que a soma de diferentes sistemas de classificação e diferentes formações discursivas, aos quais a língua recorre a fim de dar significado às coisas" (Hall, 1997a, p. 29). Nessa ótica, o reconhecimento da prática de significação das formas de vida e da prática social em cada atividade social expressa um significado e confere sentido às ações e relações sociais.

De acordo com esse entendimento, 'currículo' é uma prática de relação social, de relação de poder, e como uma prática constitutiva produz identidades sociais. Dessa maneira, afirmamos aqui que também o currículo, envolto em uma trama de significados, pode ser analisado, compreendido como um discurso, e ser visto como uma prática discursiva (Silva, 2005) que é produtora daquilo que anuncia. Tanto cultura como currículo têm efeitos de criação e produção de significados. Assim, entende-se que 'as possibilidades' estão postas em um 'entre espaço' de criação e no movimento circular da recriação, em todo e qualquer currículo.

A noção de currículo inspirada nos estudos culturais a compreende como uma 'prática cultural' e como 'prática de significação' (Silva, 2005), que seleciona e divulga sentidos sobre o mundo, sobre as relações sociais, e sobre pessoas (Paraíso, 2005). Essa compreensão está envolta no conceito de cultura. ${ }^{10}$

Nesse ponto, ponderamos a centralidade da cultura a partir de dois aspectos que Hall chama de 'substantivos' e 'epistemológicos': pela dimensão substantiva, "o lugar da cultura na estrutura empírica real e na organização das atividades, instituições e relações culturais na sociedade, em qualquer momento histórico particular" (Hall, 1997a, p. 16); e pela centralidade epistemológica, a "posição da cultura em relação às questões de conhecimento e conceitualização, em como a 'cultura' é usada para transformar nossa compreensão, explicação e modelos teóricos do mundo" (Hall, 1997a, p. 16, grifo no original) - o que inclui a noção de currículo e programas sociais.

Como nos lembram os estudiosos do currículo, a palavra pode levar a pensar em uma única coisa, o que pode ser um engano, pois, o seu sentido polissêmico, pode também tratar de diversas coisas ao mesmo tempo e todas 
estão inter-relacionadas (Llavador, 1994). Ainda nas palavras de Tomaz Tadeu, pela lente das teorias pós-críticas podemos dizer que o currículo

tem significados que vão muito além daqueles com os quais as teorias tradicionais nos confinaram. O currículo é lugar, espaço, território. O currículo é relação de poder. O currículo é trajetória, viagem, percurso. [...] O currículo é texto, discurso, documento (Silva, 1999, p.150).

A perspectiva pós-estruturalista, na qual se inserem os estudos culturais, apresenta o currículo como prática cultural e como prática de significação, assumindo papel constitutivo e não apenas determinado (Silva, 1999). Para este trabalho, o currículo é entendido como um artefato cultural, que não estaria preso nos muros de uma universidade ou de uma escola. O currículo pode estar aí, mas também poderá existir nas relações de trabalho, nos processos de aplicação de conhecimentos e aprendizado inerentes ao PMM, por exemplo. Ao considerar o currículo como artefato cultural, o tomamos como instrumento pelo qual se veiculam e se constituem valores, pensamentos, perspectivas de uma sociedade, de uma realidade cultural.

O PMM representado como possibilidade de encontro entre médicos brasileiros, médicos intercambistas e população assistida, permite novas trocas culturais que interferem na (res)significação ou contestação do que é ser médico no Brasil; onde se produz algo novo, nas relações da vida e na dimensão da produção de conhecimento. O que também podemos tomar como características 'substantivas' e 'epistemológicas' (Hall, 1997a). No caso do nosso estudo, tratamos muito mais de características substantivas - a (res)significação tomada como efeitos culturais, presentes na integração ensino-serviço, na vida empírica da assistência à saúde. Nesse encontro espaço/tempo, haverá um currículo posto entre as vivências com profissionais de outras nacionalidades, no encontro de médicos com a população que fica à margem, no encontro com o periférico, com uma prática de serviços de saúde muitas vezes distantes dos grandes centros e grandes estruturas hospitalares.

Nesse contexto do PMM como um espaço-tempo, podemos dizer que emerge um currículo. Na perspectiva da análise cultural, essa representação aproxima-se de uma prática discursiva - o que, segundo Silva (2001, p. 43, grifo no original), "não se limita a nomear coisas que estejam 'ali'; além de nomear, [o discurso] ele cria coisas: outro tipo de coisas, é verdade". Com essa inspiração foucaultiana, não levada a uma negação dos signos e sua função de designar, Silva (2001) observa que em Foucault, da mesma forma que nas análises culturais, por uma operação pós-saussureana, pós-estruturalista, a intenção é ir além de designação - já que, na busca desse algo mais, Foucault 
analisou a doença, a loucura, a sexualidade. Assim, as representações culturais, que são discursos, criam sentidos; esses sentidos são outros objetos, "que não são menos reais, em seus efeitos que a pedra que nos atinge na cabeça" (Silva, 2001, p. 44).

Ao pensarmos em um currículo inerente ao contexto do PMM, conectamono com a dimensão cultural, o conectamos com modos de vida. E ao ir mais adiante, refletimos sobre a existência de diferentes discursos que permeiam as possibilidades do PMM, que disputam e em que circulam significados e trazem à tona efeitos culturais.

\section{Possíveis efeitos culturais do Programa Mais Médicos: localizando indícios de um currículo}

As novas diretrizes curriculares, estabelecidas com parte do contexto do PMM, ao incluir como perfil profissional esperado um profissional humanista, reafirmam, portanto, uma preocupação em ultrapassar uma tradição puramente biomédica. Ao pensarmos nesses processos, conjugados com a própria subjetivação de novas dimensões além da temática instrumental e racional, afirmamos que qualificação da assistência carece de estratégias que invistam em iniciativas de um

cuidado orientado pelo reconhecimento de pessoa (o sentido de ser membro, de pertencer a um ethos, a uma cultura, a um grupo que define os próprios significados do 'eu') e de sujeito (o sentido de uma identidade a partir de uma biografia singular, articulada a uma cultura, capaz de dotar de legitimidade a autonomia de cada um) (Goulart e Chiari, 2010, p. 259, grifo no original).

Observamos efeitos que articulam aprendizagem e serviços de saúde em um novo modo de exercer a medicina. Portanto, nesse processo educação e prática médica, em que a existência de um currículo como artefato cultural coloca em movimento uma nova forma de ser médico, conforme Rodrigues, Quaresma e Monteiro (2015) assinalam sobre a estratégia de educação permanente, ${ }^{11}$ é possível observar aberturas para um trabalho (co)construtor atrelado como um coletivo de conhecimento. Nesse coletivo encontram-se vivências, o resgate de saberes da comunidade e novas práticas - o desafio dos médicos em parceria com os supervisores do PMM em estabelecer ações de educação e saúde envolvendo a população. O que, no caso estudado, começa a ser realizado com a inserção dos médicos do PMM, como uma estratégia de integração ensino-serviço.

Os profissionais médicos buscam resolução concreta dos problemas cotidianos, o que também é capaz de mudar a comunidade, já que eles debaterão os problemas de saúde que acometem aquela população. O médico reflete 
sobre sua prática, sobre os problemas do serviço que no processo gestam conhecimentos, em uma dinâmica que pensa o serviço e seus problemas, e coloca em prática uma abordagem com esse fim: solução de problemas daquela comunidade.

Um estudo da Organização Pan-Americana da Saúde indica que os gestores de saúde no Rio de Janeiro reconhecem no PMM um espaço de troca de saberes: “Desde o começo nós já sabíamos que essa experiência possibilitaria aprendizado de médicos brasileiros, que não possuíam tanto perfil e capacitação para a APS (gestor municipal)" (Opas, 2016, p. 48). Outra característica, identificada no mesmo estudo, diz respeito à abordagem médica centrada na pessoa - um dos pilares da medicina de família e de comunidade -, reconhecida como uma mudança na prática do PMM. Isso implica contato entre os médicos e a população, por múltiplos aspectos da vida da pessoa (usuário, paciente), em seu contexto pessoal, familiar e comunitário; o cuidado passa a ser mais humanizado.

Para Engstrom e colaboradores (2016), os encontros realizados no PMM provocaram mudanças nas práticas profissionais, pois o Programa constituiu um trabalho preocupado com as necessidades de saúde da população atendida, identificado pelos autores no processo educativo. O processo acontece na implementação da educação permanente, centrado na problematização e reflexão sobre o que precisa ser aplicado na assistência para atender às próprias demandas do serviço de saúde.O estudo realizado por Santos e colaboradores (2016), no Ceará, confirma efeitos culturais na prática e na troca de conhecimento entre médicos brasileiros e estrangeiros, mesmo que com pouca intensidade. O ponto principal dessa mudança diz respeito ao atendimento comunicacional e à cultura do cuidado mais humanizado. Assim, confirma uma eficácia inerente ao trabalho no Programa com ações de acolhimento, ${ }^{12}$ por exemplo, que se edificam na própria relação da integração no serviço como aprendizagem de algo novo. Aí localizamos um currículo, um processo de ensino.

Silva e Fahel (2017), em pesquisa realizada em 2017, na região metropolitana de Belo Horizonte, com médicos brasileiros e cubanos, constatou-se que houve análise do trabalho no PMM como parte fundamental do processo de aprendizagem e ampliação de conhecimento sobre o funcionamento do SUS e da APS, uma vez que, segundo os entrevistados (no caso dos médicos brasileiros), o currículo formal, pelo qual passaram na graduação, não foi trabalhado profundamente em práticas e desafios da APS. A aprendizagem no currículo, com a integração ensino-serviço como artefato, aqui não é tomada como um fim nela mesma, mas como um investimento retomado na qualidade dos serviços prestados à população - o que pode ser confirmado na fala a seguir: 
[… Eu achei muito interessante. O fazer na Atenção Primária eu fui percebendo […]. Hoje tenho um contato e aprendi mais sobre a Atenção Primária, e isso daí foi graças ao Programa Mais Médicos (MB04) (Silva e Fahel, 2017, p. 85).

Os médicos inseridos no PMM enfatizam a importância do trabalho em equipe e o apoio de todos os profissionais da enfermagem (enfermeira e técnico de enfermagem), assim como o valor do trabalho em conjunto com os agentes comunitários de saúde, como conectores entre a unidade de saúde e as famílias atendidas - o que nos leva a afirmar que há uma valorização e reconhecimento do trabalho em equipe, como parte de um processo de aprendizagem. Nesse caso, os médicos não tratam do trabalho em equipe com um sentido hierarquizado de poder, mas como um sentido de troca e interdependência no processo de trabalho em saúde. A relação educação, trabalho e saúde ${ }^{13}$ fica evidente como um tripé fundamental para o trabalho na atenção primária, como uma forma efetiva de capacitar os profissionais e que contribui para a qualidade dos serviços (Fahel, Silva e Oliveira, 2018).

Na tese de doutoramento realizada por Paula (2017), chamam a atenção os resultados do Programa que, apesar de todas as críticas recebidas, tornaram evidente a beleza de outras lutas cotidianas do serviço nas unidades básicas de saúde do sertão nordestino. Um dos entrevistados fala sobre o 'choque' que aconteceu com a chegada do PMM. O trabalho médico vivido encontrou-se com uma 'nova cultura', colocou em 'xeque' uma prática biomédica que era vista como única. É nítida a importância do encontro com essa nova cultura (local), tanto quanto uma prática de abordagem clínica mais humanizada, como afirma a autora:

Eles trouxeram pra mim [médicos cubanos] essa questão da humanização, [...] não é humanização utópica, exotérica, bonitinha, não é isso, eu estou falando de política com critérios técnicos, [...] escuta ampliada; preocupação com ambiência, fazer gestão da clínica, coisa que o brasileiro, além de não fazer, não faz nem ideia do que é isso (S3) (Paula, 2017, p. 162).

O PMM trouxe efeitos para uma prática médica que afeta positivamente os profissionais e os usuários dos serviços: a população mais carente (Paula, 2017). Assim, não seria injusto afirmar que há efeitos culturais e um processo de aprendizado inerente ao Programa. 


\section{Considerações finais}

Os estudos aqui analisados apresentam uma característica comum: conectam o trabalho dos médicos no PMM com mudanças, que chamamos de efeitos culturais, em que há um currículo posto pela busca da integralidade da assistência. Entre os resultados, verificamos que em sua essência o PMM não se limita a responder apena à falta, ou seja, o ponto não é apenas repor uma quantidade de médicos, pois o trabalho médico nessas áreas acontece em uma assistência que se faz mais humanizada. Nessa construção, podemos dizer que um currículo 'se abre' para 'escutar e olhar' o outro. O trabalho na APS se estrutura no uso de estratégias que se constroem e se conectam como potencialidade de um cuidado menos tecnicista e menos fragmentado; portanto, mais integral e humanizado.

Trata-se de um trabalho que realiza atividades como: visita domiciliar, educação permanente, acompanhamento longitudinal - o médico acompanha seus pacientes e conhece suas histórias e necessidades de saúde, pois o atendimento está ligado a uma área geográfica específica -, promoção de saúde, atividades que muitas vezes acontecem por meio de ações de educação nas unidades básicas de saúde ou em palestras realizadas em parceria com a equipe de saúde. O PMM, ao ser direcionado aos que mais necessitam de assistência médica e menos têm - a parte da população que vive em áreas vulneráveis e menos atrativas -, está produzindo efeitos não apenas na população assistida, mas também na prática médica, na forma como se exerce a medicina.

Não estamos aqui medindo a intensidade desses efeitos, mas sim a possibilidade de mudanças inerentes ao PMM - e a integração ensino-serviço nas vivências de um currículo como artefato cultural, presente nas experiências analisadas em cada trabalho que estudamos para a composição deste artigo, confirma esse movimento. Movimento que apresenta potencialidades na prática médica e nos encontros ocasionados pelo PMM, seja médico e população, seja médico e equipe de saúde. O que nos leva também a afirmar que a assistência acontece em equipe, e o médico é parte dela.

O PMM continuará demandando novas pesquisas. Ainda há lacunas entre os trabalhos acadêmicos sobre a temática, especialmente aquelas que conectam currículo e trabalho médico. De todo modo, é evidente que os processos de vivência e implementação do Programa ocasionam outros efeitos além dos efeitos culturais, que não foram foco do nosso estudo. Pelo que apresentamos, podemos afirmar que tais mudanças não são ocasionadas apenas na formação dos médicos, mas também na qualidade de vida das comunidades que receberam esses médicos. 


\section{UN CURRÍCULO EN LA INTEGRACIÓN ENSEÑANZA-SERVICIO DEL PROGRAMA MÁS MÉDICOS Y POSIBLES EFECTOS CULTURALES}

Resumen El estudio tuvo como objetivo identificar cambios en curso en la formación de profesionales de la medicina desencadenadas por las demandas del Programa Más Médicos en Brasil. Las discusiones fueron guiadas de acuerdo con formulaciones de los estudios culturales en el campo del currículo. Se analizaron artículos e informes de investigaciones sobre efectos que conectan trabajo, aprendizaje y cambios en las prácticas de médicos insertados en el Programa. El contexto de fortalecimiento y construcción del Sistema Único de Salud, algunas reformas y agendas políticas que alcanzan el currículo formal y, recientemente, la implementación del Programa Más Médicos propiamente dicho, son acciones identificadas como posibilidades creadas y como espacios donde se realizan nuevas prácticas en el interior de una cultura profesional aún biomédica/flexneriana. Los resultados confirmaron microcambios en el Programa Más Médicos que son tratados como efectos culturales, postas en práctica en la integración enseñanza-servicio, en que se verifica la aproximación de un trabajo más humanizado.

Palavras clave Programa Más Médicos; educación y salud; currículo; estudios culturales.

\section{Colaboradoras}

Maria Patrícia da Silva concebeu o estudo, desenvolveu a pesquisa e atuou em todas as etapas, até a redação e revisão do artigo. Marlucy Alves Paraíso atuou na supervisão do estudo e revisão crítica do artigo.

\section{Agradecimentos}

Ao Conselho Nacional de Desenvolvimento Científico e Tecnológico (CNPq) pelo apoio financeiro e incentivo à pesquisa, ao conceder bolsa de pós-doutorado júnior no ano de 2018-2019 para Maria Patrícia da Silva.

\section{Notas}

${ }^{1}$ No âmbito dos estudos do campo de currículo, especialmente na abordagem pós-crítica, com base em levantamento realizado no Portal Capes no período de 2013 até 2018, não foi possível localizar nenhum artigo ou tese que trabalhasse com a articulação currículo e medicina. Observamos uma ênfase em trabalhos descritivos em relação à grade curricular do curso médico, mas não na perspectiva que trabalhamos, que, inspirada nos estudos culturais, busca localizar um currículo além das universidades e do currículo formal 
como grade curricular.

${ }^{2} \mathrm{O}$ que é confirmado em diferentes estudos, como o de Santos e colaboradores (2016): a existência de uma incompatibilidade no Brasil entre a prática médica e a demanda do SUS pelo acesso universalizado e equidade.

${ }^{3}$ Plataforma de Conhecimentos do Programa Mais Médicos: uma iniciativa da Rede de Pesquisa em Atenção Primária à Saúde da Associação Brasileira de Saúde Coletiva (Abrasco), com apoio da Organização Pan-Americana da Saúde/Organização Mundial da Saúde (Opas/OMS) e do Ministério da Saúde, criada em 2015 para divulgar estudos e trabalhos relacionados ao Programa Mais Médicos.

${ }^{4}$ Material coletado quando a primeira autora, Maria Patrícia Silva, esteve como pesquisadora visitante na Fundação João Pinheiro, com bolsa de pesquisa da Fundação de Amparo a Pesquisa do Estado de Minas Gerais (FAPEMIG), com a supervisão de Murilo Fahel, em 2017.

${ }^{5}$ A escolha das universidades para a pesquisa de teses em programas de pós-graduação procedeu-se de maneira aleatória, devido à conveniência.

${ }^{6}$ As críticas foram veiculadas em diversos jornais escritos e on-line, dos quais cabe mencionar o jornal on-line Setor Saúde, de São Paulo que, em 10 de agosto de 2015, publicou matéria na qual criticava fortemente o PMM. Um dos pontos criticados era o fato de que o Brasil estaria financiando a - por eles chamada - Ditadura de Cuba. Em 27 de julho de 2013, o portal intitulado Empresa Brasileira de Comunicação tratou de algumas questões consideradas polêmicas em relação ao Programa, principalmente advindas do Conselho Nacional de Medicina (CFM). Entre elas, criticava o governo que, segundo a instituição, colocava a responsabilidade dos problemas do SUS nos médicos; outro ponto era a não aceitação pelo CFM da abertura de vagas para graduação de novos médicos. Em 2014, o jornal Brasil Debate, ao analisar o PMM, lembrou que muitas críticas foram feitas pela contratação de médicos cubanos para o Programa Mais Médicos, a partir de 2013, especialmente por parte de setores ligados ao PSDB. No entanto, poucos se lembram de que o presidente Fernando Henrique Cardoso já havia contado com o auxílio humanitário de médicos da ilha.

${ }^{7}$ Para mais informações sobre o significado da APS, indicamos Starfield (2001), Mendes (2011), Fahel, Silva e Oliveira (2018).

${ }^{8}$ Para Hall (1997b), há três teorias que debatem o uso de representação: a reflexiva, a intencional e a construcionista. Esta última melhor se ajusta ao uso do autor, que considera a linguagem como um produto social em que os significados são construídos por meio dos sistemas de representação.

9 Para maior aprofundamento nesse debate, consultar Stuart Hall (2016) em Cultura e representação. Mesmo nesta obra, o autor reconhece o seu caráter inacabado: "o que nós oferecemos aqui é, esperamos, um balanço relativamente claro, embora experimental, de um conjunto de ideias complexas de um projeto não acabado" (Hall, 2016, p. 111). O que fizemos foi uma aproximação descritiva sobre representação e estudos culturais, para demonstrar como compreendemos culturas, currículos e o próprio contexto inerente ao Programa Mais Médicos. Mas temos clareza de que sua compreensão vai além do que aqui foi exposto. 
${ }^{10}$ Ainda que o sentido de cultura entre os antropólogos passe por diferentes conceituações e não esteja limitado a uma única coisa. Por exemplo, temos em Geertz (1978) 'cultura como uma teia de símbolos', tecida pelos homens, onde estão normas, crenças, significados.

${ }^{11}$ A educação permanente em saúde é parte das estratégias e programas do SUS, instituídas desde 2004, por meio de portaria do Ministério da Saúde. Desde então, sua implantação é um desafio para o sistema de saúde. Dentre outros fatores, o esperado era a transformação do trabalho do SUS seguindo três fundamentos centrais: micropolítica do trabalho, com inspiração marxista e visão ontológica do trabalho; método da roda; e problematização/ aprendizagem significativa, voltada para questões reais, problemas e necessidades do trabalho em saúde, de modo a localizar também soluções para os problemas identificados pelo grupo. É importante entender que os três elementos estão entrelaçados e em uma lógica que possibilitaria educar um sujeito com compromisso e capacidade de gerar solução de maneira eficaz e eficiente (Lemos, 2016).

${ }^{12} \mathrm{O}$ acolhimento é uma estratégia prevista no Programa Nacional de Humanização, criado pelo Ministério da Saúde em 2003. Valorizar os sujeitos é oportunizar maior autonomia, a ampliação da sua capacidade de transformar a realidade em que eles vivem, por meio da responsabilidade compartilhada, da criação de vínculos solidários, da participação coletiva nos processos de gestão e de produção de saúde (Brasil, 2003).

${ }^{13}$ Nas falas dos médicos abordados, não identificamos nenhuma menção a um trabalho de educação permanente, estabelecido ou ministrado pelos médicos a outros membros da equipe.

\section{Referências}

BRASIL. Política Nacional de Humanização: HumanizaSUS. 2003. Disponível em: < http:// portalms.saude.gov.br/acoes-e-programas/politica-nacional-de-saude-bucal/legislacao/693acoes-e-programas/40038-humanizasus $>$. Acesso em: ago. 2018.

BRASIL. Portaria n. 2.488, de 21 de outubro de 2011. Aprova a Política Nacional de Atenção Básica, estabelecendo a revisão de diretrizes e normas para a organização da atenção básica, para a Estratégia Saúde da Família (ESF) e o Programa de Agentes Comunitários de Saúde (PACS). Disponível em: <http://bvsms.saude.gov.br/bvs/saudelegis/gm/2011/prt2488_21_10_2011.html>. Acesso em: dez. 2016.

BRASIL. Lei n. 12.871, de 22 de outubro de 2013. Institui o Programa Mais Médicos, altera a lei n. 8.745, de 9 de dezembro de 1993, e n. 6.932, de 7 de julho de 1981, e dá outras providências. Disponível em: <http://www. planalto.gov.br/ccivil_03/_Ato2011-2014/2013/ Lei/L12871.htm>. Acesso em: dez. 2016.

BRASIL. Ministério da Saúde. Secretaria de Gestão do Trabalho e da Educação na Saúde. Programa Mais Médicos: dois anos - mais saúde para os brasileiros. Brasília: Ministério da Saúde, 2015.

CORADINI, Odaci L. A formação da elite médica, a Academia Nacional de Medicina e a França como centro de importação. Revista Estudos Históricos, Rio de Janeiro, v. 1, n. 35 , p. 3-22, jul. 2005. Disponível em: <http:// bibliotecadigital.fgv.br/ojs/index.php/reh/ article/view/2232>. Acesso em: maio 2018.

COSTA, Marisa V.; SILVEIRA, Rosa H.; SOMMER, Luís H. Estudos culturais, educação e pedagogia. Revista Brasileira de Educação, Rio de Janeiro, n. 23, p. 36-61, maio-ago. 
2003. Disponível em: <http://www.scielo.br/ scielo.php?script $=$ sci_arttext\&pid $=$ S141324782003000200004\&lng $=$ en $\& n r m=$ iso $>$. Acesso em: maio 2018.

COSTA, Marisa V.; WORTMANN, Maria L.; BONIN, Iara T. Contribuições dos estudos culturais às pesquisas sobre currículo: uma revisão. Currículo sem Fronteiras, Pelotas, v. 16, n. 3, p. 509-541, set.-dez. 2016. Disponível em: <http://www.curriculosemfronteiras. org/voll6iss3articles/costa-wortmann-bonin. pdf $>$. Acesso em: maio 2018.

CYRINO, Eliana G. et al. O Programa Mais Médicos e a formação no e para o SUS: por que a mudança? Escola Anna Nery Revista de Enfermagem, Rio de Janeiro, v. 19, n. 1, p. 5-10, 2015.

ENGSTROM, Elyne M. et al. O supervisor e as estratégias educacionais dos encontros locorregionais no Programa Mais Médicos do Brasil: reflexões acerca de concepções e práticas. Tempus: Actas de Saúde Coletiva, Brasília, v. 10, n. 1, p. 241-252, mar. 2016. Disponível em: <http://www.tempusactas.unb.br/index. php/tempus/article/view/1863/1594>. Acesso em: abr. 2018.

FAHEL, Murilo C. X.; SILVA, Maria P.; OLIVEIRA, Daniele. A trajetória da atenção primária à saúde no Brasil: de Alma Ata ao Programa Mais Médicos. Belo Horizonte: Fundação João Pinheiro, 2018.

GEERTZ, Clifford. A interpretação das culturas. Rio de Janeiro: Zahar, 1978.

GIOVANELLA, Ligia et al. A provisão emergencial de médicos pelo Programa Mais Médicos e a qualidade da estrutura das unidades básicas de saúde. Ciência \& Saúde Coletiva, Rio de Janeiro, v. 21, n. 9, p. 2.697-2.708, set. 2016. Disponível em: <http://www.scielo. br/scielo.php?script=sci_arttext\&pid=S1413$81232016000902697 \& \operatorname{lng}=\mathrm{en} \& \mathrm{nrm}=\mathrm{iso}>$. Acesso em: set. 2017.

GIRARDI, Sábado N. et al. Impacto do Programa Mais Médicos na redução da escassez de médicos em atenção primária à saúde. Ciência \& Saúde Coletiva, Rio de Janeiro, v. 21, n. 9, p. 2.675-2.684, set. 2016. Disponível em: $<$ http://www.scielo.br/scielo.php?script=sci arttext\&pid=S1413-81232016000902675\&lng $=$ en $\& n r m=i s o>$. Acesso em: set. 2017.

GOULART, Bárbara N. G.; CHIARI, Brasília M. Humanização das práticas do profissional de saúde: contribuições para reflexão. Ciência \& Saúde Coletiva, Rio de Janeiro, v. 15, n. 1, p. 255-268, jan. 2010. Disponível em: $<$ http://www.scielo.br/scielo.php?script=sci arttext\&pid=S1413-81232010000100031\&lng =en \&nrm=iso>. Acesso em: dez. 2016.

HALL, Stuart. Cultural studies and its theoretical legacies. In: MORLEY, David; KUAN-HSING, C. (eds.). Stuart Hall: critical dialogues in cultural studies. London: New York: Routledge, 1996. p. 261-274.

HALL, Stuart. A centralidade da cultura: notas sobre as revoluções culturais do nosso tempo. Revista Educação \& Realidade, Porto Alegre, v. 22, n. 2, p. 15-46, 1997a.

HALL, Stuart. The work of representation. In: HALL, Stuart (org.). Representation: cultural representation and cultural signifying practices. London/Thousand Oaks/New Delhi: Sage/Open University, 1997b. p. 13-74.

HALL, Stuart. Cultura e representação. Rio de Janeiro: Ed. PUC-Rio, 2016.

LEMOS, Cristiane L. S. Educação permanente em saúde no Brasil: educação ou gerenciamento permanente? Ciência \& Saúde Coletiva, Rio de Janeiro, v. 21, n. 3, p. 913-922, mar. 2016. Disponível em: <http://www.scielo. br/scielo.php?script=sci_arttext\&pid=S1413$81232016000300913 \& \operatorname{lng}=\mathrm{en} \& \mathrm{nrm}=\mathrm{iso}>$. Acesso em: jul. 2018.

LLAVADOR, Francisco B. Las determinaciones y el cambio del currículo. In: ANGULO, José F.; BLANCO, Nieves (coords.). Teoría y desarrollo del currículo. Málaga: Ediciones Aljibe, 1994. p. 369-383. 
MACHADO, Maria H. (coord.). Os médicos no Brasil: um retrato da realidade. [online]. Rio de Janeiro: Editora Fiocruz, 1997. Disponível em: <http://books.scielo.org/id/bm9qp/pdf/ machado-9788575412695-03.pdf $>$. Acesso em: dez. 2015.

MENDES, Eugênio V. As redes de atenção à saúde. Brasília: Opas, 2011.

MENICUCCI, Telma M. G. Público e privado na politica de assistência à saúde no Brasil: atores, processos e trajetória. Rio de Janeiro: Editora Fiocruz, 2007.

ORGANIZAÇÃO PAN-AMERICANA DA SAÚDE (OPAS). Programa Mais Médicos no município do Rio de Janeiro: mais acesso, equidade e resolutividade na APS. Brasília: Opas, 2016. (Série Estudos de Caso sobre o Programa Mais Médicos 2). Disponível em: <http:// maismedicos.bvsalud.org/programa-maismedicos-no-municipio-do-rio-de-janeiro/> . Acesso em: mar. 2018.

PAGLIOSA, Fernando L.; DA ROS, Marco A. O relatório Flexner: para o bem e para o mal. Revista Brasileira de Educação Médica, Rio de Janeiro, v. 32, n. 4, p. 492-499, dez. 2008. Disponível em: <http://www.scielo.br/ scielo.php?script $=$ sci_arttext\&pid $=$ S0100$55022008000400012 \& \operatorname{lng}=\mathrm{en} \& \mathrm{nrm}=\mathrm{iso}>$. Acesso em: ago. 2017.

PARAÍSO, Marlucy A. Contribuições dos estudos culturais para o currículo. Presença Pedagógica, Belo Horizonte, v. 10, n. 55, p. 53-61, jan.-fev. 2004.

PARAÍSO, Marlucy A. O autogerenciamento de docentes em sua formação e em seu trabalho. Educação e Pesquisa, São Paulo, v. 31, n. 2, p. 173-188, maio-ago. 2005.

PAULA, Juliana B. Análise do ciclo político do Programa Mais Médicos: cooperação Cuba e Brasil e seus efeitos no trabalho médico. 226 f. Tese (Doutorado em Saúde Global e Sustentabilidade) - Faculdade de Saúde Pública, Universidade de São Paulo, São Paulo, 2017. Disponível em: < http://www.teses.usp.br/teses/ disponiveis/6/6140/tde-04012018-165436/ pt-br.php>. Acesso em: ago. 2018.

RODRIGUES, Cybelle C. P.; QUARESMA, Mariana S. M.; MONTEIRO, Ronaldo C. Educação em saúde no Programa Mais Médicos para o Brasil: o papel do supervisor no processo educacional. Tempus: Actas de Saúde Coletiva, Brasília, v. 9, n. 4, p. 151-158, dez. 2015. Disponível em: <http://www.tempusactas.unb.br/index. php/tempus/article/view/1730/1479>. Acesso em: abr. 2018.

SANTOS, João B. F. et al. Médicos estrangeiros no Brasil: a arte do saber olhar, escutar e tocar. Saúde e Sociedade, São Paulo, v. 25, n. 4, p. 1.003-1.016, dez. 2016. Disponível em: $<$ http://www.scielo.br/scielo.php?pid=S0104$12902016000401003 \& \mathrm{script}=\mathrm{sci}$ abstract\&tlng =pt>. Acesso em: ago. 2017.

SILVA JUNIOR, Aluisio G.; ANDRADE, Henrique S. Formação médica no Programa Mais Médicos: alguns riscos. Ciência \& Saúde Coletiva, Rio de Janeiro, v. 21, n. 9, p. 2.670-2.671, 2016. Disponível em: <https://www.scielosp.org/article/ ssm/content/raw/?resource_ssm_path=/media/ assets/csc/v2 ln9/1413-8123-csc-21-09-2670. pdf $>$. Acesso em: ago. 2017.

SILVA, Maria P.; FAHEL, Murilo C. X. Programa Mais Médicos em Minas Gerais: uma análise sobre os principais desafios e avanços presentes no processo de trabalho e assistência na atenção básica em municípios da Região Metropolitana de Belo Horizonte/MG. Relatório de Pesquisa - Fundação João Pinheiro, Belo Horizonte, 2017.

SILVA, Tomaz T. Documentos de identidade: uma introdução às teorias do currículo. Belo Horizonte: Autêntica, 1999.

SILVA, Tomaz T. O currículo como fetiche: a poética e a política do texto curricular. 2. ed. Belo Horizonte: Autêntica, 2001.

STARFIELD, Bárbara. Atención primaria: equilibrio entre necesidades de salud, servicios y tecnología. Barcelona: Masson, 2001. 